\title{
ИННОВАЦИОННЫЕ ВЫЗОВЫ ОБЩЕСТВУ И ЭКОНОМИКЕ В УСЛОВИЯХ ДИДЖИТАЛИЗАЦИИ
}

\section{INNOVATIVE CHALLENGES TO SOCIETY AND ECONOMY IN THE CONDITIONS OF DIGITALIZATION}

D. Havin

P. Bekker

Summary. The article analyzes the current challenges of world development as a result of technology development, digitalization of the economy. Particular emphasis is placed on the importance of not only innovations as such, but the predominant importance of introducing new technologies into the economic activities of economic entities, which increases the competitiveness and well-being of national economies as a whole. At the same time, the advanced development of technologies leads to the polarization of the labor market, the washing out of low-skilled labor, which, taking into account the constantly growing number of the world's inhabitants, requires a solution. The results presented in the article are based on the works of both domestic and foreign scientists.

Keywords: digitalization, economic transformation, digital economy, robotization, technological innovation, the fourth industrial revolution, innovation management.
$\Pi$ родолжающееся распространение новой коронавирусной инфекции и опережающее развитие цифровых технологий является императивом для экономистов и учёных. Для нивелирования негативных последствий распространения новой инфекции большинство мировых компаний внедряет передовые технологические разработки, позволяющие обеспечивать не только дистанционную работу (отсутствие необходимости присутствовать непосредственно в офисе), но и взаимодействие с партнёрами, контрагентами, клиентами без дополнительных трансакционных издержек.

Тенденция внедрения новых технологий во все сферы жизни человека приводит к тому, что существовавшие технологические ограничения стираются $[1,8]$. Инновации проявляются не только в производственной сфере, но и в социальной, а взаимное влияние указанных областей лишь усиливается. В результате становится очевидной взаимосвязь производственного и социального секторов. Глобальные компьютерные
Хавин Дмитрий Валерьевич

ФГБОУ ВО «Нижегородский государственный архитектурно-строительный университет», Нижний

Новгород

odonngasu@yandex.ru

Беккер Павел Райнгольдович

ФГБОУ ВО «Нижегородский государственный архитектурно-строительный университет», Нижний

Новгород

BeckerPR@yandex.ru

Аннотация. В статье проведён анализ актуальных вызовов мирового развития в следствие развития технологий, цифровизации экономики. Особый акцент сделан на значимости не только инноваций как таковых, а преобладающей значимости внедрения новых технологий в хозяйственную деятельность экономических субъектов, что повышает конкурентоспособность и благосостояние национальных экономик в целом. В то же время, опережающее развитие технологий приводит к поляризации рынка труда, вымыванию низкоквалифицированного труда, что с учётом постоянно растущего числа жителей планеты требует решения. Результаты, приведенные в статье, основываются на трудах как отечественных, так и зарубежных ученых.

Ключевые слова: диджитализация, трансформация экономики, цифровая экономика, роботизация, технологические инновации, четвёртая промышленная революция, управление инновациями.

технологии, большие данные способствуют социальной динамике информационного общества. В настоящее время интернет используется в концепции мира вещей, который основан на так называемых мультиагентных технологиях, позволяющих соотносить реальный мир с виртуальным, без участия человека, что отражено на рисунке 1.

Как и все основные технологические достижения в историческом контексте, автоматизация рассматривается не только как потенциальный источник (например, повышения производительности), но и как угроза прежним формам организации труда $[15,16]$. Прогресс в области искусственного интеллекта (ИИ) и технологий автоматизации может серьезно изменить рынки труда. Современные достижения кроме положительных результатов, заключающихся в повышении производительности, несут и негативные эффекты, связанные с замещением отдельных видов работ и даже целых профессий. Рост автоматизации и изменения структуры рынка кадров, происходящие в эпоху возрастающе- 


\section{Непрерывный круглосуточный медицинский}

мониторинг на основе вживленных датчиков

и др.

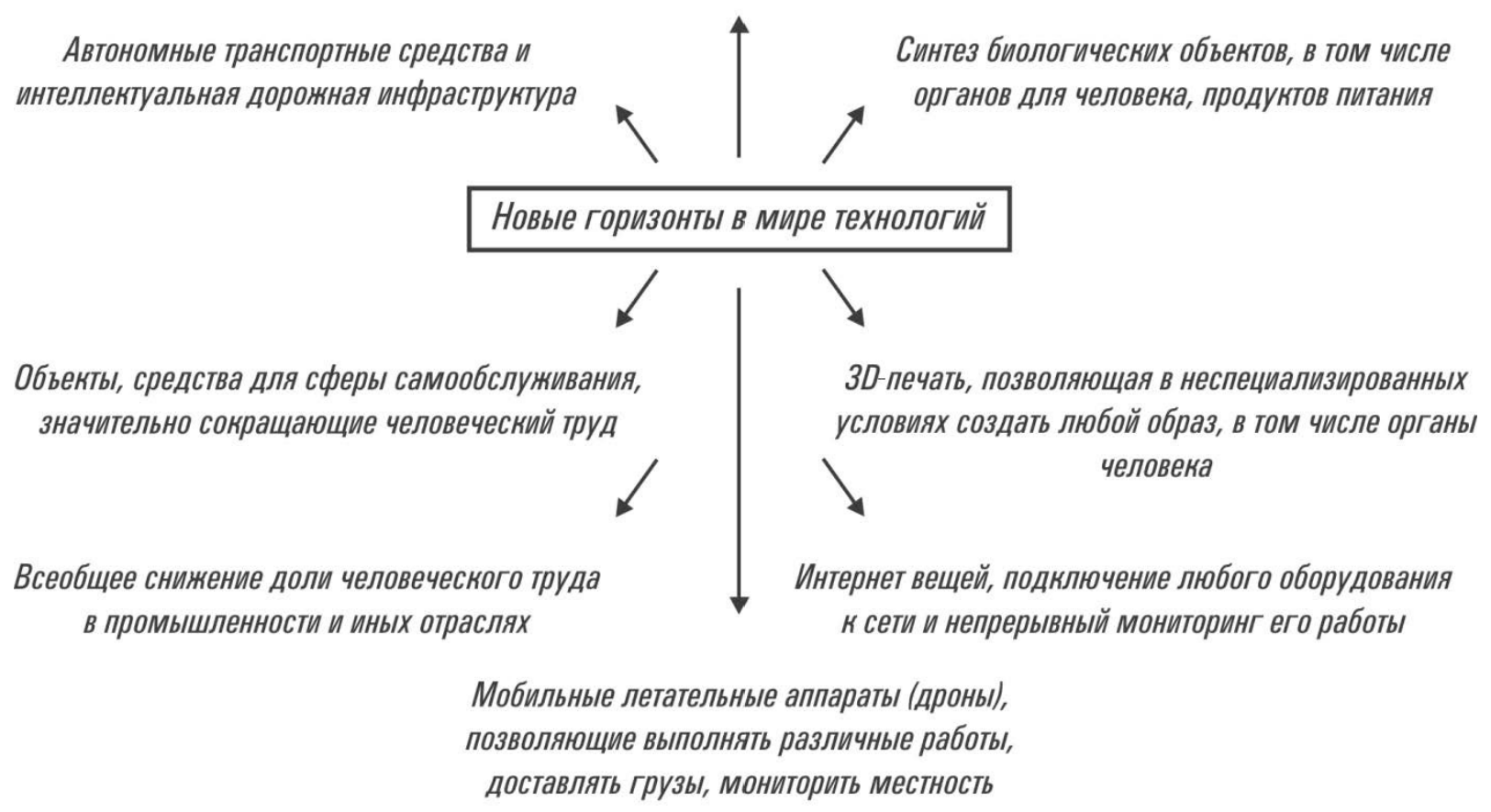

Рис. 1. Мировые технологические тенденции

го экономического неравенства, вызывают опасения по поводу массовой безработицы в целых сегментах рынка труда.

Традиционная экономическая теория предполагает, что технологический прогресс увеличивает спрос на такие факторы производства, как труд или капитал. Однако эта модель игнорирует важный эффект автоматизации - происходящие изменения структуры кадров. В основе каждого исторического процесса индустриализации лежит автоматизация многих трудоемких задач. Производство стало более быстрым и рентабельным, при этом не только рабочие перестают выполнять задачи, но и отдельные специалисты, чья работа поддаётся автоматизации. Большинство мировых компаний проводят политику «совместной автоматизации», когда робототехника используется для поддержки людей, а не для их замены. Автоматизация таким образом призвана поддержать работников, выполняя повторяющиеся, скучные или опасные операции, которые часто приносят меньше пользы, но должны реализовываться.

Задачи, подвергающиеся автоматизации, включают как монотонную рутинную физическую работу, так и сбор, обработку и первичный анализ данных. Если повторяющиеся задачи автоматизировать, то эти работники высвободят время на задачи с добавленной стоимо- стью. Учитывая это, становится ясно, что организации, инвестирующие в автоматизацию, получат огромное конкурентное преимущество. Наряду с оказанием помощи работникам в менее ценных аспектах их работы, автоматизация также создает новые возможности для работы, создавая спрос на новые высококвалифицированные технические должности $[3,5]$. Такой переход к высококвалифицированным техническим специалистам благодаря автоматизации в конечном итоге приведет к увеличению чистой занятости.

Отдельные компании вовсе избавляются от человеческого труда в ряде бизнес-процессов. К примеру, реализуя продукции через автоматизированные установки в сфере общественного питания, используя роботов вместо курьеров при доставке товара и иные частные случаи [2, 7]. Анализируя уровень заработной платы сотрудников высоко конкурентной и эффективной экономики США, можно констатировать, что предприниматели не стремятся увеличивать вознаграждение сотрудников, при этом, производительность растёт опережающими темпами (рис. 2). Данный феномен находит своё отражение в множестве исследований, предприниматели не просто заинтересованы максимизировать рентабельность бизнеса, но и сократить до минимума необходимый персонала путём подмены современными технологиями $[9,10]$. 
$300 \%$

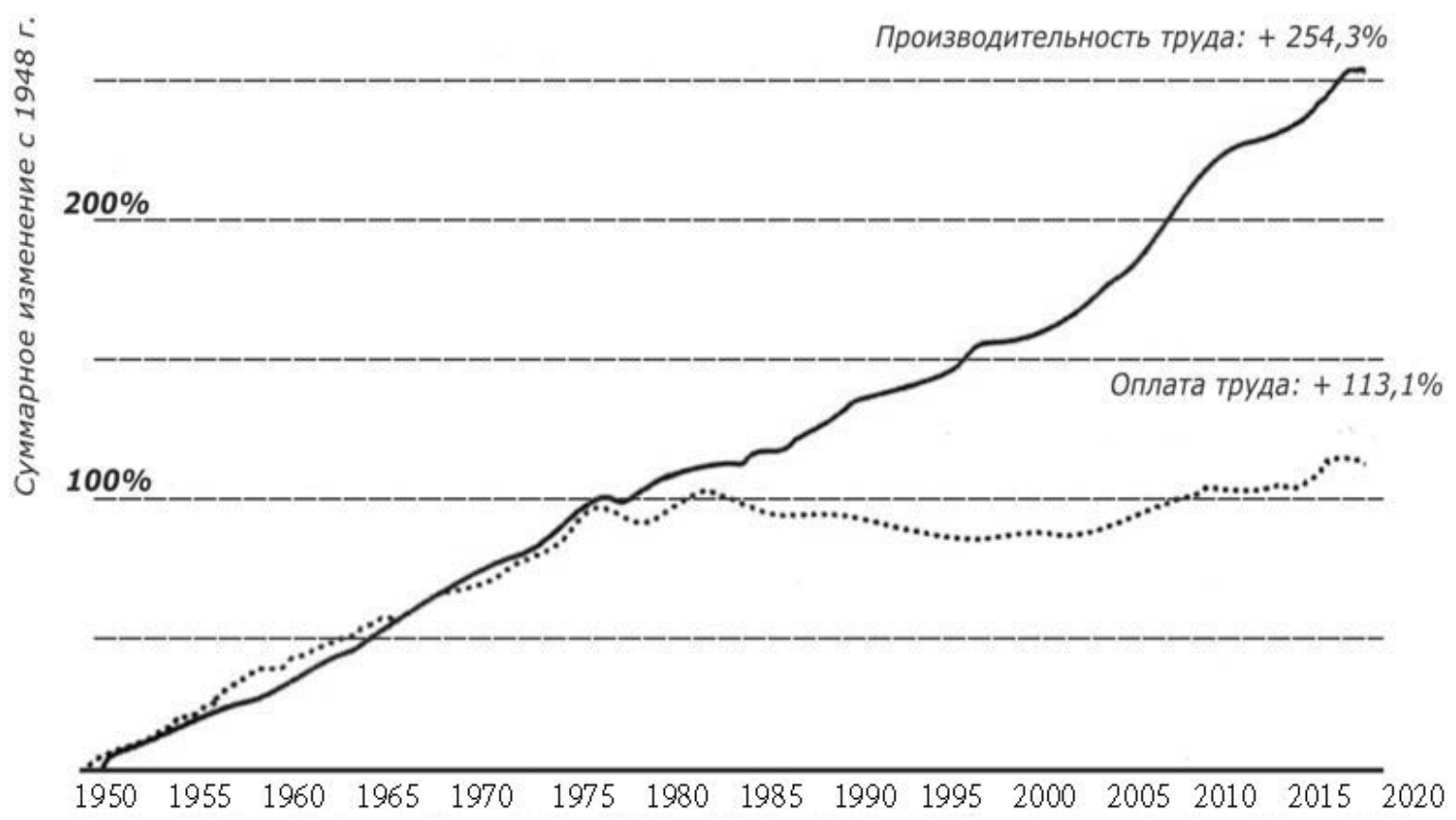

Рис. 2. Уровень оплаты труда сотрудников и уровень производительности труда в США [11]

Исследования, посвящённые влиянию экономических кризисов на рынок труда, показали, что рабочие места среднего класса наиболее подвержены риску безработицы, а восстановление рынка труда в первую очередь основано на профессиях, не требующих высшего образования, применения специальных знаний, опыта. Сфера базовых услуг, досуга, развлечений в первую очередь обеспечивает экономический подъём в посткризисный период. Таким образом, именно высококвалифицированные кадры наиболее конкурентных отраслей приоритетно подвержены риску. Эта закономерность в меньшей мере относится к специалистам, работающим в наукоёмких фундаментальных областях человеческих знаний [11]. Особенно ярко данная тенденция показала себя в период восстановления, который обозначился после 2009 г.

Процесс, поддающийся анализу с начала 2009 г., продолжает всё более ярко проявляться в результате новых кризисных явлений. Ситуация с распространением новой коронавирусной инфекции в 2020 г. показала, насколько работники базовых профессий незащищены от циклической безработицы. Больницы развитых стран, в том числе в США закупают роботов-уборщиков для больниц с коронавирусом. Также крупные больницы развернули специализированных медсестер-роботов с технологией удаленного наблюдения за пациентами. Другие больницы, наряду с продуктовы- ми магазинами, ресторанами и крупными предприятиями розничной торговли, внедрили роботы-пылесосы, которые используют УФ-инструменты для уничтожения бактерий и вирусов. Покупка больницей ультрафиолетовых роботов подчеркивает, как пандемия коронавируса ускоряет движение к автоматизации в экономике США — на этот раз не только с целью заставить машины более эффективно выполнять работу людей, но и уничтожать микробы и ограничивать контакты с людьми изза угроз общественному здоровью.

Замена людей машинами продолжится и в ближайшем будущем, поскольку компании переходят от режима выживания и приспособления к выяснению того, как действовать в условиях постоянных рисков пандемии. Согласно докладу экономистов Массачусетского технологического института и Бостонского университета, к 2025 году роботы могут заменить еще до 2 миллионов рабочих в производстве, поскольку машинам не нужно изолироваться, им не нужно брать отпуск. В частности, муниципалитеты в США, которым пришлось закрыть свои перерабатывающие предприятия, теперь используют роботов с искусственным интеллектом для сортировки тонны пластика, бумаги и стекла. Всё это создает долгосрочные риски для низкооплачиваемых рабочих, которые обычно выполняют работу по уборке помещений. Люди из рабочего класса уже сталкиваются с повышенным риском поте- 
ри рабочих мест из-за автоматизации во всей экономике во время рецессий $[4,6]$.

Как и в случае с изменением потребительских привычек, которые могут стать постоянными даже после завершения текущего кризиса, нынешняя ситуация может стимулировать значительное распространение роботов в будущем. Многие компании, которые раньше вообще не рассматривали возможность использования роботов, теперь используют их в обычных операциях. В будущем успех этих пилотных программ, вероятно, окажет большое влияние на инвестиции в технологии и может подтолкнуть организации к более широкому использованию робототехники.

Результатом социально-экономического кризиса в совокупности с развитием современной техники и технологий на рынке труда стало снижение потребности в профессиях в области торговли, индустрии развлечений, туризма и в целом сферы услуг. Краткосрочный спад в мировой экономике был обусловлен временными ограничениями как на передвижение, так и на деятельность отдельных секторов экономики. В свою очередь, представители бизнеса для снижения подобных рисков в будущем перестраивают привычные процессы взаимодействия с покупателями, контрагентами используя бесконтактные способы доставки, оплаты, реализуя потенциал современных роботов и электронных сервисов. Таким образом, профессии, которые вчера были реальностью, сегодня теряют свою актуальность и уходят в прошлое. В дополнение к кризисным явлениям, ускоряющим внедрение инноваций, следует отметить тенденцию кардинального изменения структуры рынка труда в результате закономерного развития общества, получившей название «поляризация рынка труда» [12]. Под поляризацией рынка труда в первоначальном понимание, понимается вытеснение профессий среднего класса, тогда как роль низкооплачиваемого труда, роль рабочих профессий, которые невозможно заменить роботами, и роль высокооплачиваемых специалистов возрастает [12]. Кроме того, технологии меняют требования к сотрудникам: чтобы дополнять роботов (а не конкурировать с ними), людям необходимо развивать такие качества, как креативность, эмоциональный интеллект и когнитивная гибкость, а компаниям следует больше инвестировать в обучение персонала, в их переподготовку.

Происходящие структурные изменения рынка труда изучены экономистом профессором Массачусетского технологического института Дэвидом Аутором. Его заслуженно считают родоначальником изучения феномена поляризации рынка кадров в результате публикации серии работ, описывающих процесс вымывания из экономики представителей среднего класса. По мнению
Д. Аутора, наиболее сильному влиянию подвержен ряд профессий, в том числе ремесленники, подсобные рабочие, офис-менеджеры, операторы машин и др. За анализируемый период более чем в 30 лет на рынке труда США, Д. Аутором установлено, что в рассматриваемых сферах уровень занятости снизился более чем на $10 \%$ [12]. Данные, приведённые в исследовании, позволяют сделать вывод, что кризисные явления лишь являются дополнительным катализатором ускорения естественного процесса по снижению потребности в ряде базовых профессий и оптимизации персонала предприятий.

Из исследований экономистов Европейского центрального банка, посвящённых настоящему феномену следует, что не только рынок США подвержен подобной тенденции, но и другие страны с развитой экономикой, в том числе страны Европы [13, 14]. В развитие исследования Д. Аутора европейские учёные выявили, что изменения рынка труда проявляется и в количестве отработанного времени по видам профессий. Тенденция по сокращению рабочего времени по видам профессий проявляется по-разному, то есть неравномерно. Постепенное сокращение труда для работников с низкой долей интеллектуального труда быстрее проявляется, нежели чем для работников с высокой долей интеллектуального труда, где снижение занятости в часах практически незаметно. Таким образом, ещё одна составляющая структурного изменения рынка труда заключается в неравномерной разгрузке кадров с течением времени. Работодатели снижают нагрузку на сотрудников рабочих профессий, подменяя их труд не только с помощью автоматизации и роботизации, но и за счёт большего вовлечения высококвалифицированных специалистов.

Таким образом, на основе современных тенденций можно отметить феномен поляризации рынка труда и подъема экономики после рецессии и спада без создания дополнительных рабочих мест. Профессиональная специализация является основным драйвером экономического развития. Развитие технологий ведет к неизбежности процесса автоматизации функций многих профессий. Данное обстоятельство способствует как резкому росту структурной безработицы, так и поляризации рынка труда. Новейшая волна диджитализации должна кардинальным образом изменить каждый аспект экономики от производства до дистрибуции, от управления до розницы. Проведенный анализ классификации основных вызов глобального экономического развития свидетельствует о том, что инновационный прогресс - это процесс превращения идеи в конкретный продукт, технологию или бизнес для внедрения и улучшения конкретной области, одновременно приводящий к поляризации рынка труда. В чём и заключается основной негативный фактор, который только предстоит определить. 
ЛИТЕРАТУРА

1. Будзинская 0.В. «Безлюдное производство»: страх или неизбежная реальность? // Инновации и инвестиции. 2018. № 10.

2. Ганьшина Е.Ю. Цифровизация как источник возмещения капитала — решения, меняющие бизнес // Инновации и инвестиции. 2019 . № 9.

3. Еремин В.В. Роботизация и занятость: отложенная угроза // Мир новой экономики. 2019. № 1.

4. Звонова Е.А. Трансформация мировой экономики и пандемия // Экономика. Налоги. Право. 2020. № 4.

5. Катаев А.Н. Роль автоматизации бизнес-процессов российских нефтегазовых компаний в повышении эффективности их деятельности // Инновации и инвестиции. 2018. № 5.

6. Петровская Н.Е. Влияние новых технологий и роботизации на занятость в США // Управление. 2020. № 3.

7. Скворцова Н.А., Лебедева 0.А., Сотникова Е.А. Влияние информационных технологий на развитие бизнеса // Теоретическая и прикладная экономика. 2018. № 1.

8. Соколов И.А., Мишарин А.С., Куприяновский В.П., Покусаев 0.Н., Ларин О.Н. Цифровая экономика Западной Австралии - умные горнорудные и нефтегазовые предприятия, железные дороги, морские порты и формализованные онтологии // International Journal of Open Information Technologies. 2018. № 6 .

9. Форд М. Роботы наступают: Развитие технологий и будущее без работы / Мартин Форд; Пер. с англ. — М.: Альпина нон-фикшн, 2016. — 430 с.

10. Харин А.А., Рождественский А.В., Коленский И.Л. Управление инновационными процессами // Directmedia, 2016 ISBN: 5447555450.471 C.

11. Ben Casselman. "Low Pay Clouds Job Growth" // Wall Street Journal, April 3, 2013

12. David Autor. "The Polarization of Job Opportunities in the U.S. Labor Market: Implications for Employment and Earnings" // The Center for American Progress and The Hamilton Project, April 2010, pp. 8-9.

13. Davide Dottori. "Robots and employment: evidence from Italy," //Questioni di Economia e Finanza (Occasional Papers) 572, Bank of Italy, Economic Research and International Relations Area, 2020.

14. Dias da Silva, Antonio and Petroulakis, Filippos and Laws, Athene, Hours of Work Polarisation? (October, 2019) // ECB Working Paper No. $2324,2020$.

15. PwC Report The new hire: How a new generation of robots is transforming manufacturing. URL: http://www.pwc.com/us/en/industrialproducts/assets/ industrial-robot-trends-in-manufacturing-report.pdf(Accessed 01.08.2021).

16. Robots could replace 250,000 UK public sector workers // The Guardian. 2017. 6 Feb. (Accessed: 25.07.2021)

(c Хавин Дмитрий Валерьевич ( odonngasu@yandex.ru ), Беккер Павел Райнгольдович ( BeckerPR@yandex.ru )

Журнал «Современная наука: актуальные проблемы теории и практики»

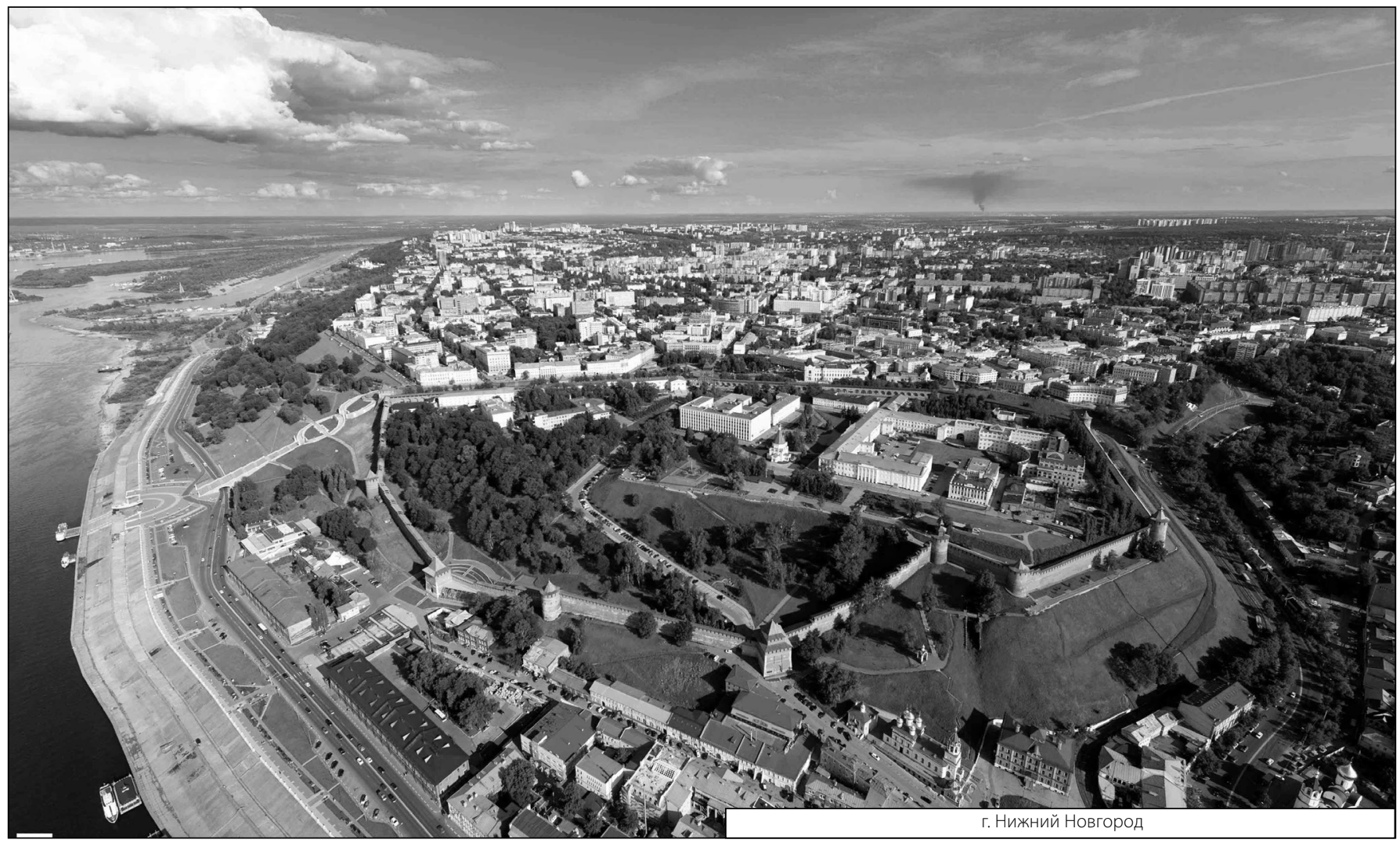

